\title{
Investigating small-scale variations of the recent accumulation rate in coastal Dronning Maud Land, East Antarctica
}

\author{
Helgard ANSCHÜTZ, ${ }^{1}$ Olaf EISEN, ${ }^{1,2}$ Hans OERTER, ${ }^{1}$ Daniel STEINHAGE, ${ }^{1}$ \\ Mirko SCHEINERT ${ }^{3}$ \\ ${ }^{1}$ Alfred-Wegener-Institut für Polar- und Meeresforschung, Postfach 120161, D-27515 Bremerhaven, Germany \\ E-mail: hanschuetz@awi-bremerhaven.de \\ ${ }^{2}$ Versuchsanstalt für Wasserbau, Hydrologie und Glaziologie (VAW), Eidgenössische Technische Hochschule, ETH-Zentrum, \\ CH-8092 Zürich, Switzerland \\ ${ }^{3}$ Institut für Planetare Geodäsie, Technische Universität Dresden, D-01062 Dresden, Germany
}

\begin{abstract}
The accumulation rate on Potsdam Glacier, East Antarctica, and its spatial and temporal variations are examined using ground-penetrating radar, snow samples and firn-core studies. Physical properties in snow samples and along firn cores provide distributions of density with depth, showing only small spatial variation. Counting of peaks in $\delta^{18} \mathrm{O}$ along the firn cores yields an age-depth distribution that is transferred to the stratigraphy of isochronal internal layers observed with radar. From two radar horizons we determine the spatial accumulation pattern, averaged over the periods 1970-80 and 1980-2004. The shape of internal layers indicates an ablation area at the eastern margin of the investigation area. Accumulation rates show a very high spatial variability, with a mean value of $141 \mathrm{~kg} \mathrm{~m}^{-2} \mathrm{a}^{-1}$ for the period $1970-2004$ and a standard deviation of almost $50 \%$. Mean temporal variation of only a few per cent throughout the investigated area for the observed time interval is much less than the spatial variations. The mean accumulation values are somewhat less than values reported before from this region. Accumulation pattern and surface topography are linked in a way indicating that wind-borne redistribution of snow significantly contributes to the observed spatial variations of accumulation rates. The accumulation data and their variability complement and validate present and future satellite studies of Antarctica's mass balance.
\end{abstract}

\section{INTRODUCTION}

Surface mass-balance studies of the Antarctic ice sheet are of vital importance for an enhanced understanding of the Earth's climate and its changes (Rignot and Thomas, 2002; Van der Veen, 2002), as the polar regions are able to contribute significantly to global sea-level change (Wingham and others, 1998). It is therefore crucial to determine the mass fluxes of the Antarctic ice sheet, for example by using remote-sensing techniques and satellite-based methods. Variations of accumulation and density on temporal and spatial scales also influence the relation between elevation changes and changes in gravity and mass. Knowledge of spatial and temporal patterns of ice-mass changes provides key information especially for validation of the time-varying gravity field as sensed by the Gravity Recovery and Climate Experiment (GRACE). (For a general overview of the GRACE mission see Tapley and others, 2004.) For this reason, small-scale variations of the accumulation rate play a significant role and need to be investigated closely by ground-borne operations.

Accumulation data are usually derived from firn cores, snow pits or stake readings (Isaksson and Karlén, 1994; Melvold and others, 1998; Kreutz and others, 2000; Oerter and others, 2000), but they yield only information about the local accumulation rate at the probing location. In recent years, ground-penetrating radar (GPR) measurements have proved a useful tool to map relative variations in surface mass balance over larger areas and connect snow pits and firn-core drilling sites (e.g. Richardson and others, 1997; Pinglot and others, 2001; Sinisalo and others, 2003; Rotschky and others, 2004; Spikes and others, 2004).
Internal reflection horizons (IRHs) detected by GPR can be used to match signals found in different firn cores along the GPR profiles and assist proper correlations between the firn cores. The observed IRHs arise from contrasts of dielectric permittivity in the subsurface. In the upper hundreds of metres, density has the most significant influence, affecting the real part of the dielectric permittivity (Fujita and others, 1999). IRHs are shown to be of isochronal origin (Eisen and others, 2004; Vaughan and others, 2004), and from their estimated age and a density-depth distribution the mean accumulation rate for a certain period can be calculated.

In this study, we present GPR and firn-core data from a relatively small area in East Antarctica where no reliable accumulation data of high resolution have been available so far. High-frequency GPR measurements were carried out on Potsdam Glacier in Neuschwabenland, the coastal part of Dronning Maud Land (DML), during the Antarctic summer season 2003/04. Shallow firn cores were drilled at selected locations along the radar profiles. Two IRHs are traced throughout several GPR profiles and dated by a reference firn core. The firn-core analyses give travel-time-depth and density-depth relations that can be used to derive the regional accumulation pattern from these tracked IRHs.

\section{STUDY AREA}

The study area is located south of the Schirmacheroase and north of Wohlthat Massif (Fig. 1a). Most parts of Potsdam Glacier are above 1000 ma.s.l. and have a mean annual air temperature below $-20^{\circ} \mathrm{C}$ (Bormann and Fritzsche, 1995). The average ice thickness is $>1200 \mathrm{~m}$, and subglacial 
topography is characterized by deep valleys with some subglacial highs (Damm and Eisenburger, 2005; Meyer and others, 2005). The surface elevation declines from almost $1350 \mathrm{~m}$ a.s.l. in the southwestern part of the study area to about 850 ma.s.l. in the northeastern part. Accumulation dominates in this region, with the exception of small ablation areas around several nunataks. In the most northeasterly part of this glacier, near and east of the Schirmacheroase, a large ablation area is found that reaches up to the eastern Wohlthat Massif (Bormann and Fritzsche, 1995). Analysis of a firn core drilled at $70^{\circ} 58^{\prime} \mathrm{S}, 11^{\circ} 22^{\prime} \mathrm{E}$, about $15 \mathrm{~km}$ away from our radar profiles, showed snow and firn with some ice layers down to $27 \mathrm{~m}$ depth. From 27 to $51 \mathrm{~m}$, stratified ice layers were found, and below $50 \mathrm{~m}$ unstratified ice with small bubbles occurred (Bormann and Fritzsche, 1995 and references therein).

Ice-flow studies in this region have been undertaken, among others, by Korth and Dietrich (1996). They carried out differential global positioning system (GPS) measurements and stake readings along the GPS signals on traverse lines going from Novolazarevskaya station to Humboldtfjella and Gruberfjella, respectively (Fig. 1a). The flow pattern of Potsdam Glacier has also been deduced by interferometric synthetic aperture radar (SAR) analysis (Dietrich and others, 1999), as well as the line of highest flow velocity, hereinafter referred to as the main flowline. The velocities in the direction of glacier flow in the study area increase from about $20-30 \mathrm{~m} \mathrm{a}^{-1}$ in the higher-elevation parts to $70-80 \mathrm{~m} \mathrm{a}^{-1}$ in the lower region. The vertical velocity is unknown. Glacier flow is mainly divergent in the higher-elevation parts of the glacier, whereas in the lowerelevation parts laterally convergent flow is observed (M. Bäßler and others, unpublished information).

\section{METHODS}

\subsection{GPR and GPS data}

During the 2003/04 expedition, a $50 \mathrm{~km}$ long radar survey line was collected along the main flowline of Potsdam Glacier. Three cross-profiles were surveyed, each one being $8 \mathrm{~km}$ long (Fig. 1b). We used a commercial RAMAC radar system (Malå Geoscience, Sweden) with a bistatic shielded $500 \mathrm{MHz}$ antenna that was connected to the central unit via fibre optic cables. Data were stored on a Husky Px5 computer. The GPR antenna was mounted behind a Nansen sledge pulled by a snowmobile at an average speed of $\sim 5 \mathrm{~km} \mathrm{~h}^{-1}$. Traces were recorded every $0.5 \mathrm{~m}$, triggered by a distance wheel. Each trace consisted of 2048 samples in a $400 \mathrm{~ns}$ time window, thus mapping the upper $\sim 35-38 \mathrm{~m}$ of the snowpack. Differential GPS data were collected simultaneously with GPR data. The roving station was mounted on the snowmobile, and two reference stations were situated at the field camp, i.e. about $1 \mathrm{~km}$ south of point F33 (see Fig. 1), and at the Schirmacheroase, respectively. The GPS data were collected every $1 \mathrm{~s}$ using a Trimble 4000SSi receiver and a choke-ring antenna. Processing of GPS data yields positions for the GPR profiles as well as surface elevation. The relative accuracy between the differential GPS points is generally in the range of several millimetres to a few centimetres for longitude and latitude, and of some centimetres to about one decimetre for the elevation. However, due to the movement of the roving station over severe sastrugi fields, we assume that actual accuracy declines to some centimetres for longitude and latitude and reaches a few decimetres for

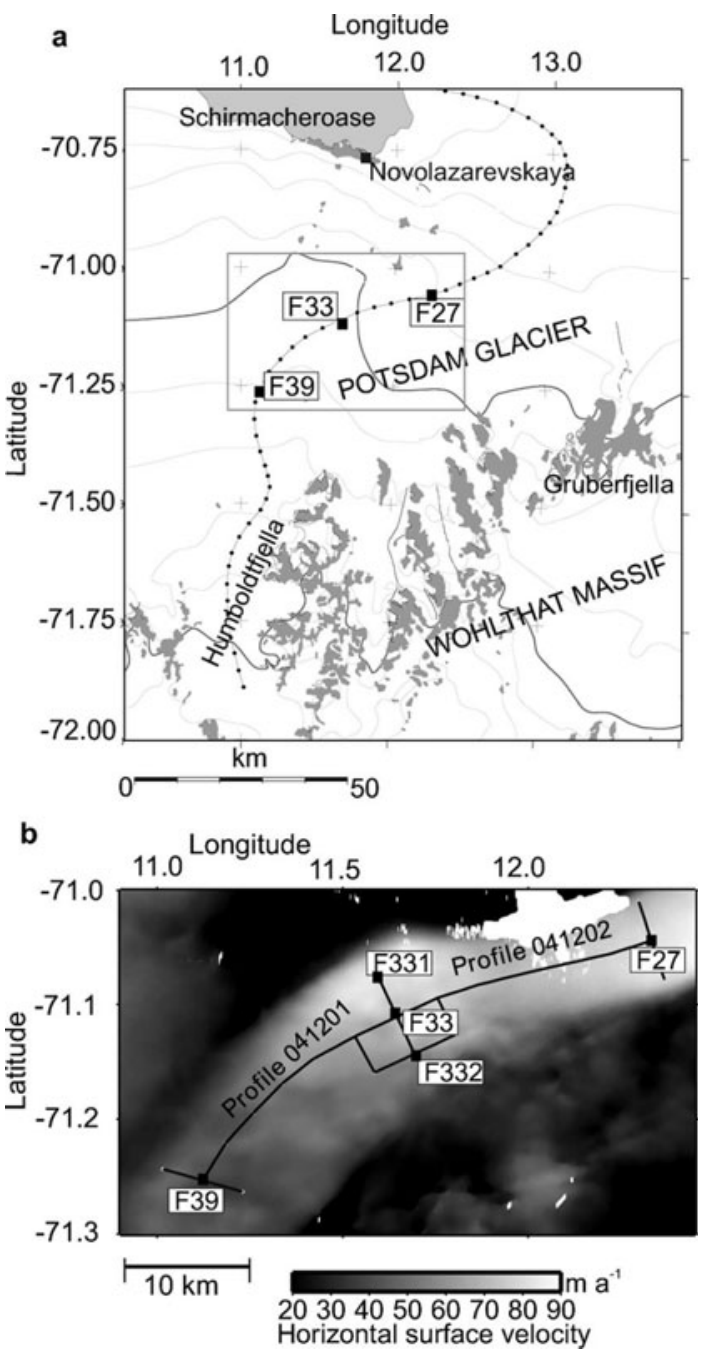

Fig. 1. (a) Overview of the study area. Black line: main flowline of Potsdam Glacier (Bäßler and others, 2003); black squares: start/end points of GPR profiles along the flowline. (Map source: Antarctic Digital Database 4.0.) Grey lines: contour lines of elevation at $200 \mathrm{~m}$ intervals; thick grey line: $1000 \mathrm{~m}$ contour line; large grey rectangle: area depicted in (b). (b) Sketch of GPR profiles (black lines) and firncore locations (black squares) with point names (Fxxx). Profiles 041201/041202 correspond to the main flowline; glacier flow is from left to right. Distances F39-F33 and F33-F27 amount to $25 \mathrm{~km}$ each. Greyscale indicates magnitude of glacier flow velocity.

the elevation. The radar data were processed using Paradigm Geophysical FOCUS version 5.0 software by applying gain control, filtering using a bandpass Butterworth filter with cutoff frequencies of 350 and $850 \mathrm{MHz}$, and correction for the first arrival of the direct wave. From the processed radargrams, IRHs were tracked semi-automatically using Landmark OpenWorks release 2003.0 software. Within the depth section covered by the firn cores (given below), two internal horizons could be tracked throughout more than one GPR profile.

\subsection{Firn cores and snow samples}

At five locations (Fig. 1b; Table 1) along the radar profiles, shallow, 12.5-13.5 $\mathrm{m}$ deep, firn cores were drilled. At the same sites $2 \mathrm{~m}$ deep snow pits were dug which were probed in intervals of $5 \mathrm{~cm}$, giving 40 samples per pit. The density of the snow samples was determined in situ from the weight and the known volume of the probing cylinder. 

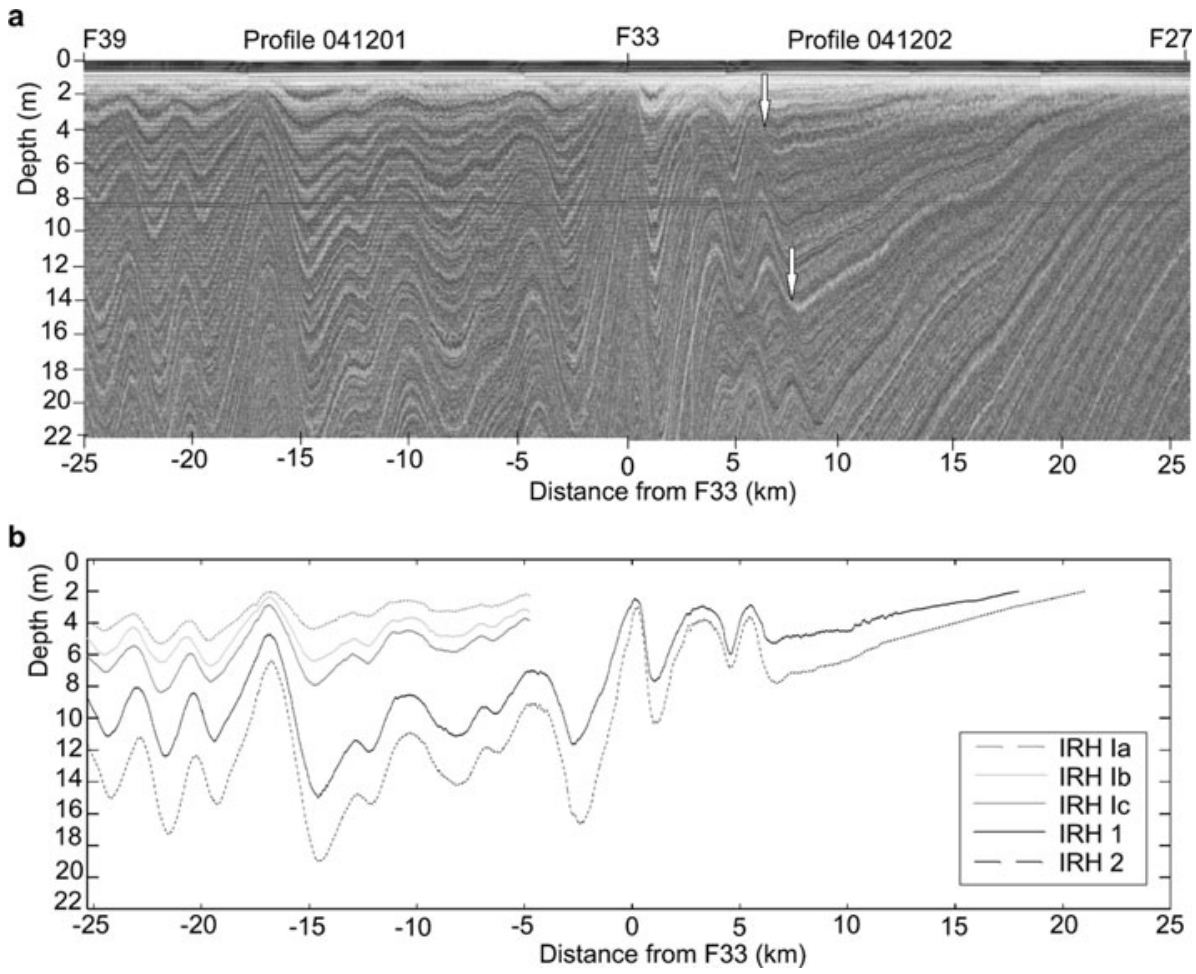

Fig. 2. (a) Processed radargrams from profiles 041201 and 041202 . The white arrows mark the IRHs chosen to determine the approximate beginning of the transition zone from accumulation to ablation. (b) Depth distribution of tracked and dated IRHs. Black solid line: IRH 1 (1980); black dashed line: IRH 2 (1970); grey dashed line: IRH la (1995); light grey line: IRH Ib (1992); dark grey line: IRH IC (1989).

The firn cores and snow samples were transported to Germany and analyzed in the cold laboratory at the Alfred Wegener Institute, Bremerhaven, for physical and chemical properties. Snow-sample data were used to link firn-core data to the surface due to poor core quality in the upper $1-2 \mathrm{~m}$ of drilling. The $\delta^{18} \mathrm{O}$ ratio was determined by mass spectrometry for both the firn cores as well as the snow samples. Firn-core analysis covered measurements of density using gamma-attenuation profiling (GAP) as well as dielectric profiling (DEP) that yield density, dielectric permittivity and electrical conductivity of the firn (Wilhelms, 1996, 2005).

\subsection{Determination of accumulation rates}

We derive distributions of electromagnetic wave speed and cumulative mass with depth from the firn-core data. The mean values of density, dielectric permittivity and conductivity of all five firn cores are used, since no further information about the lateral variations of those parameters between the firn-core drilling sites is available. Cumulative snow mass is obtained by integration of the mean density profile derived from the GAP measurements. Calculation of electromagnetic wave speed from DEP-derived parameters follows the procedure described by Eisen and others (2002). Error estimates are given below. Since the firn cores reach only a depth of about $12 \mathrm{~m}$ below the surface, the data of the two-way-travel-time (TWT)-depth and cumulative-massdepth models were extrapolated down to $25 \mathrm{~m}$ depth. Extrapolation was done using the MATLAB ${ }^{T M}$ polyfit routine by fitting a third-order polynomial (Richardson and others, 1997; Frezzotti and others, 2005) yielding a correlation coefficient of $R=0.90$. Age-depth profiles are determined by counting the $\delta^{18} \mathrm{O}$ peaks which indicate summer maxima (McMorrow and others, 2004 and references therein).
Consistent dating of the different firn cores proved difficult due to local variations in the $\delta^{18} \mathrm{O}$ profiles which did not allow clear identification of maxima and minima for every firn core. However, firn core $\mathrm{F} 39$ shows a $\delta^{18} \mathrm{O}$ profile with pronounced maxima and minima (Fig. $3 \mathrm{~d}$ ), so it was used as a reference core for interpreting the radar data. F332 could likewise be dated sufficiently by its $\delta^{18} \mathrm{O}$ profile. However, since the tracked IRHs do not reach up to this core, F332 could not be used for dating the GPR layers. The two tracked horizons (IRH 1 and IRH 2; see Fig. 2b) are dated against $\mathrm{F} 39$ by comparing the depth of the respective $\mathrm{IRH}$ at the coring location with the depth-age scale of the firn core. The depth values for the IRHs at the drilling location are $8.65 \mathrm{~m}$ (IRH 1) and $11.55 \mathrm{~m}$ (IRH 2), and their estimated time of origin is 1970 and 1980, respectively, \pm 2 years for each dating. Three more IRHs (IRH la, Ib and Ic; see Fig. 2b) that could only be tracked throughout the uppermost $\sim 20 \mathrm{~km}$ along the main flowline are also dated by the depth-age scale of F39: their estimated times of origin are 1995, 1992 and 1989 ( \pm 1 year for each dating).

The accumulation rate along the GPR profiles can be calculated by dividing the cumulative mass difference of two selected IRHs by their respective age difference.

\subsection{Estimation of errors}

Errors in our density-depth distribution are assumed to be up to $14 \%$ at $12 \mathrm{~m}$ depth, determined from the difference between the mean values (i.e. the model used) and F39 and F27, respectively (Fig. 4c). This includes errors from the density measurements using GAP which are up to $10 \mathrm{~kg} \mathrm{~m}^{-3}$ (Wilhelms, 2005). Accuracy of DEP-derived parameters is within 1\% (Wilhelms, 1996). Errors in TWT-depth conversion using DEP data are up to $1 \%$ as shown by Eisen and others (2002). Errors in calculations of the cumulative mass 
Table 1. Location of firn cores

\begin{tabular}{llccc}
\hline Firn core & Point name* & $\begin{array}{c}\text { Latitude } \\
{ }^{\circ}\end{array}$ & $\begin{array}{c}\text { Longitude } \\
{ }^{\circ} \mathrm{E}\end{array}$ & $\begin{array}{c}\text { Elevation } \\
\text { m }\end{array}$ \\
\hline FB0401 & F33 & 71.110709 & 11.646268 & 1013 \\
FB0402 & F332 & 71.143130 & 11.693510 & 1076 \\
FB0403 & F39 & 71.253401 & 11.122667 & 1315 \\
FB0404 & F331 & 71.078270 & 11.599180 & 1008 \\
FB0405 & F27 & 71.044023 & 12.332327 & 848 \\
\hline
\end{tabular}

*As in Figure 1b.

from the density profiles are likewise up to $1 \%$ due to error propagation. The dating uncertainty of the two IRHs used for determination of area-wide accumulation rates is \pm 2 years. Errors in tracking of IRHs are up to $\pm 2 \mathrm{~ns}$, which yields depth variations of up to $\pm 0.2 \mathrm{~m}$. However, for the two dated IRHs (IRH 1 and 2) this latter uncertainty does not affect the estimated age since $8.65 \pm 0.2 \mathrm{~m}$ and $11.55 \pm 0.2 \mathrm{~m}$ still correspond to the years 1980 and 1970, respectively (Fig. 4d). From analytic error propagation, the overall rootmean-square error in accumulation rates becomes $11.5 \%$ for profile 041201 . The largest error was found to be $20 \%$. We therefore assume that the accumulation values presented in this paper are accurate within about $12 \%$ on average. Errors from ray-path geometry due to the separation of transmitting and receiving antenna are neglected, since transmitter and receiver are separated by only $0.18 \mathrm{~m}$. For the same reason, refraction within the snowpack can be neglected (Sinisalo and others, 2003).

\section{RESULTS}

\subsection{GPR profiles}

In the processed radargrams the undulations of internal layers can clearly be seen (Fig. 2a). Internal layers show large slopes along profile 041201. At some locations the vertical distance between separate layers is very small (e.g. at -16 to $-17 \mathrm{~km})$, whereas a few kilometres away the same layers are spaced more widely (e.g. from about -10 to $-15 \mathrm{~km}$ ). Comparable undulating patterns have been reported before in DML, for example by Richardson-Näslund (2001). Closely spaced layers indicate areas with less accumulation, whereas more widely spaced layers are associated with regions of higher accumulation. Along profile 041202 (Fig. 2a), layers ascend in the direction of glacier flow (with the exception of the local undulations in the first $6-7 \mathrm{~km})$. Such patterns are characteristic for ablation areas and the transition from an accumulation area to an ablation area, where internal horizons come to the surface due to surface erosion. However, it is not possible to resolve actual ablation from very low accumulation by GPR internal layering. A layer outcropping at the surface at a certain location along the GPR profile would only yield zero values for accumulation or ablation for this point. Besides, the isochronal layers cannot be traced up to the surface since they are lost within the time window of the direct wave (here the upper $\sim 20 \mathrm{~ns}$, equivalent to $\sim 2 \mathrm{~m}$; Fig. 2a). Assuming zero advection, ascending layers with angles $<90^{\circ}$ relative to the surface would still provide accumulation, albeit low values (Fig. 2a, near $x=25 \mathrm{~km}$ ). Without advection, therefore, only layers emerging perpendicularly at $90^{\circ}$ indicate
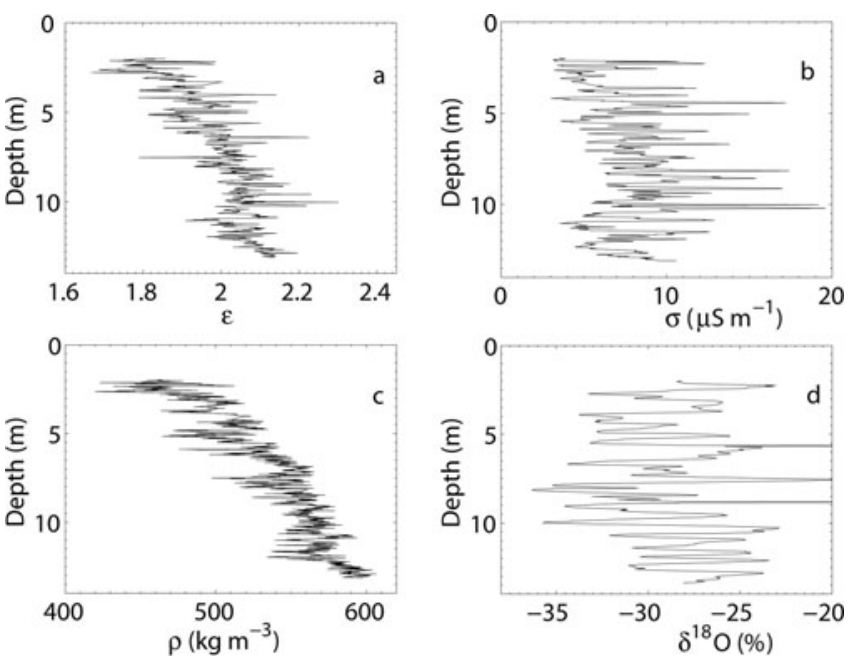

Fig. 3. Data from firn core F39: (a) dielectric permittivity; (b) electrical conductivity; (c) density (from GAP); and (d) $\delta^{18} \mathrm{O}$.

ablation. Yet in our case we can conclude from the ascending IRHs that the transition zone from accumulation to ablation is present and visible in the radargram. Since we do have advection effects here, we cannot clearly define the beginning of the ablation area. Thus, we do not address the actual ablation area, but rather the transition zone where very low accumulation and also local ablation might occur. We define the beginning of this zone by the point where the first IRH would reach the surface. Using two different IRHs marked by the white arrows in Figure $2 \mathrm{a}$, and extrapolating from their respective slopes the points where they would reach the surface, results in $x=21.35 \mathrm{~km}$ and $x=23.84 \mathrm{~km}$, respectively. Since these IRHs could not be dated, we are unable to apply a sufficient correction for glacier flow velocity. By choosing one very shallow and one rather deep IRH we can at least conclude that the transition zone from very low accumulation to ablation starts at this part of Potsdam Glacier between about 21 and $24 \mathrm{~km}$ downstream of F33. Thus, the actual ablation area is to be expected slightly farther down-glacier, which is in accordance with the description of Bormann and Fritzsche (1995) and Horwath and others (2006).

\subsection{Firn-core data and density distribution}

The parameters derived from the firn-core analysis are depicted in Figure 3 for firn core F39. Dielectric permittivity as well as density increase with depth (Fig. $3 a$ and c), but the parameters do not reach values of solid ice $\left(\rho=917 \mathrm{~kg} \mathrm{~m}^{-3}\right)$ within the depth section covered by the firn cores. Some of the peaks of the density coincide with observed ice lenses in the firn core.

Figure 3 shows the models for TWT-depth (Fig. 3b) and cumulative mass-depth (Fig. 3c) as derived from the mean values and from the 'extreme' cores, i.e. the core with the lowest mean density (F39) and the core with the highest mean density (F27). Down to about 5-6 m depth, the density values of the different firn cores are very similar (Fig. 4a). Below this depth they start to differ slightly, up to $\sim 100$ $150 \mathrm{~kg} \mathrm{~m}^{-3}$ at about $12 \mathrm{~m}$ depth. In the upper $6-7 \mathrm{~m}$, density variations within one specific firn core are usually larger than the variations between the different cores at the same depth. Generally, F27 shows the largest density values. This core 
Table 2. Accumulation values in the study area, given in $\mathrm{kg} \mathrm{m}^{-2} \mathrm{a}^{-1}$. Note that the top three rows (GPR-based accumulation rates) represent spatial means from the study area, whereas the bottom two rows (firn-core derived accumulation series) represent temporal accumulation means for the time period covered by the firn cores at the respective coring locations

\begin{tabular}{lccccc}
\hline Method & Period & Mean acc. & Std* & Min. & Max. \\
\hline GPR-IRHs & $1970-80$ & 142 & 51 & 18 & 335 \\
GPR-IRHs & $1980-2004$ & 140 & 48 & 27 & 318 \\
GPR-IRHs & $1970-2004$ & 141 & 47 & 31 & 290 \\
Firn core F332 & $1966-2003$ & 161 & 39 & 60 & 327 \\
Firn core F39 & $1968-2003$ & 176 & 30 & 96 & 289 \\
\end{tabular}

*One-fold standard deviation in \% of the mean.

was drilled on the lower-elevation part of the glacier where the radar data indicate an ablation area nearby. Farther east a blue-ice area is found (Bormann and Fritzsche, 1995; Korth and Dietrich, 1996; Horwath and others, 2006) where the surface density should be higher than in the firn areas. Thus it can be assumed that density in the study area will increase in the direction of glacier flow, which is in accordance with our findings. However, density values of F27 are still in the range of firn density and do not reach the density of solid ice. Therefore we conclude that this part of the glacier is dominated by firn, at least in the uppermost $12 \mathrm{~m}$.

\subsection{Accumulation rates}

The mean accumulation rate in the study area is derived for the periods 1970-80, 1970-2004 and 1980-2004, with 2004 corresponding to the surface at the time of data collection (Table 2). The depth distribution of the dated IRHs is depicted in Figure 2b. Taking into account a mean glacier flow velocity of $45 \mathrm{~m} \mathrm{a}^{-1}$ results in the accumulation distribution along the main flowline (Fig. 5c). Furthermore, annual accumulation rates are obtained from the two dated firn cores (Table 2; Fig. 5a).

\section{DISCUSSION OF ACCUMULATION FEATURES}

\subsection{Temporal characteristics}

Comparing the mean values of the GPR-derived accumulation rates from Table 2, we conclude that the spatial variability exceeds the mean temporal variability for the periods considered. This has been reported before at other places in East Antarctica, for example by Frezzotti and others (2005). The temporal variations in accumulation rates derived from GPR measurements for the periods 1970-80 and $1980-2004$ are about $1.5 \%$, calculated from the mean values of the respective periods. However, interannual variability obtained from the two dated firn cores (Fig. 5a) is high, showing one-fold standard deviations of $30 \%$ and $39 \%$, respectively (Table 2 ). Differences in per cent of the firn-core mean values range from $-63 \%$ to $+103 \%$ for $\mathrm{F} 332$ and from $-46 \%$ to $+65 \%$ for F39 (Fig. $5 \mathrm{c}$ ). A mean over 10 years of the accumulation series obtained from the firn cores indicates a slight decrease at F332 and an even smaller increase at F39 for the period 1984-93 (Fig. 5b). Although the timescales are rather short, this suggests that the accumulation pattern comprising the last 30 years is quite stable on decadal scales in relation to the annual variability.
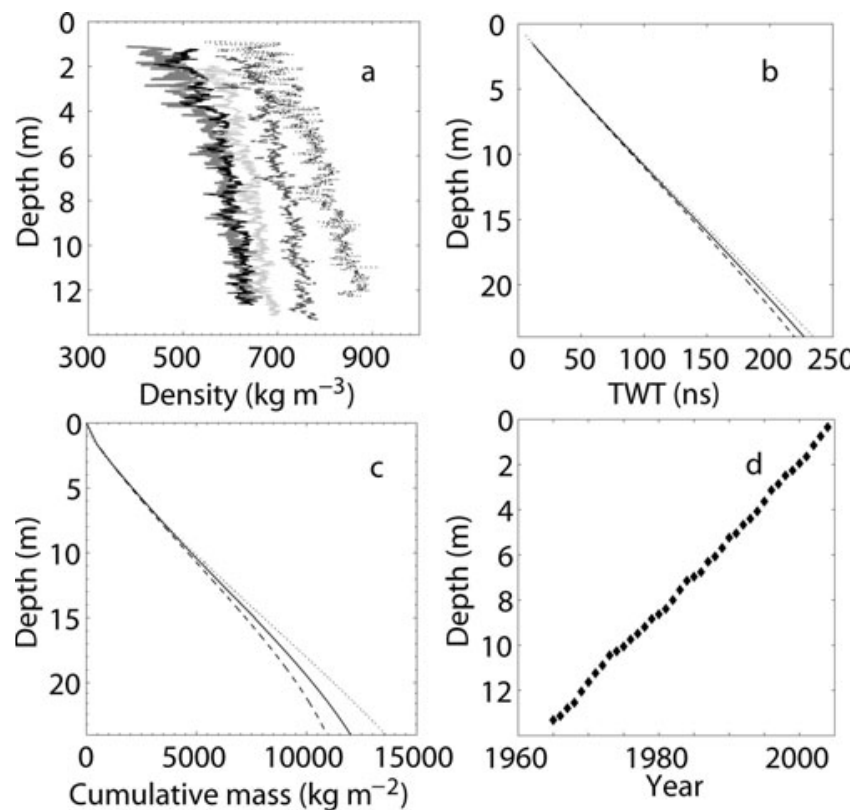

Fig. 4. (a) Density distribution of all firn cores. Thick grey line: F33; solid black line: F332; light grey line: F39; dark grey line: F331; black dotted line: F27. The density plots are offset by intervals of $50 \mathrm{~kg} \mathrm{~m}^{-3}$ in order to distinguish the individual cores. (b, c) Model for TWT-depth (b) and cumulative mass-depth (c). In each plot the solid line corresponds to the model derived from the mean values, the dashed line to the model derived from F39, and the dotted line to the model derived from F27. (d) Depth-age scale as derived from the dating of F39.

\subsection{Spatial characteristics}

Generally, our mean core-derived accumulation rates are about $12-23 \%$ higher than the average GPR-based accumulation rates in the investigation area. We therefore conclude that the spatial representativity of the firn cores is limited, as has been discussed before for West Antarctica (Spikes and others, 2004) and the western part of DML (RichardsonNäslund, 2001). The spatial variability of GPR-derived accumulation rates along the main flowline is very high (Fig. 6c). Differences in per cent of the mean range from $-81 \%$ to $+125 \%$ for the period $1980-2004$, showing an undulating pattern. Accumulation rates show strong spatial gradients of up to $105 \mathrm{~kg} \mathrm{~m}^{-2} \mathrm{a}^{-1} \mathrm{~km}^{-1}$, with pronounced changes from increasing to decreasing accumulation in the direction of glacier flow, sometimes even within $<1 \mathrm{~km}$. For example, going $1 \mathrm{~km}$ upstream from near F33 yields a 10 -fold increase in accumulation (from about 30 to $330 \mathrm{~kg} \mathrm{~m}^{-2} \mathrm{a}^{-1}$ ) for the interval 1970-80. Average accumulation gradients are on the order of $23 \mathrm{~kg} \mathrm{~m}^{-2} \mathrm{a}^{-1} \mathrm{~km}^{-1}$. Generally, a decrease in accumulation in the direction of glacier flow is visible. The linear trend along profiles 041201/041202 amounts to $-4.9 \mathrm{~kg} \mathrm{~m}^{-2} \mathrm{a}^{-1} \mathrm{~km}^{-1}$. This is in accordance with the observation that IRHs tend to come to the surface at lower elevations on the main flowline (Fig. 2a).

Surface slope and slope of accumulation (Fig. 6d) show regular undulations similar to those in surface elevation (Fig. 6a and b) and in accumulation (Fig. 6c). Anschütz and others (2006) show that these undulations are likely caused by a feedback system between atmosphere and cryosphere similar to the features ruling the genesis of megadunes on the polar plateau (Frezzotti and others, 2002). Comparable association between surface slope and accumulation has 


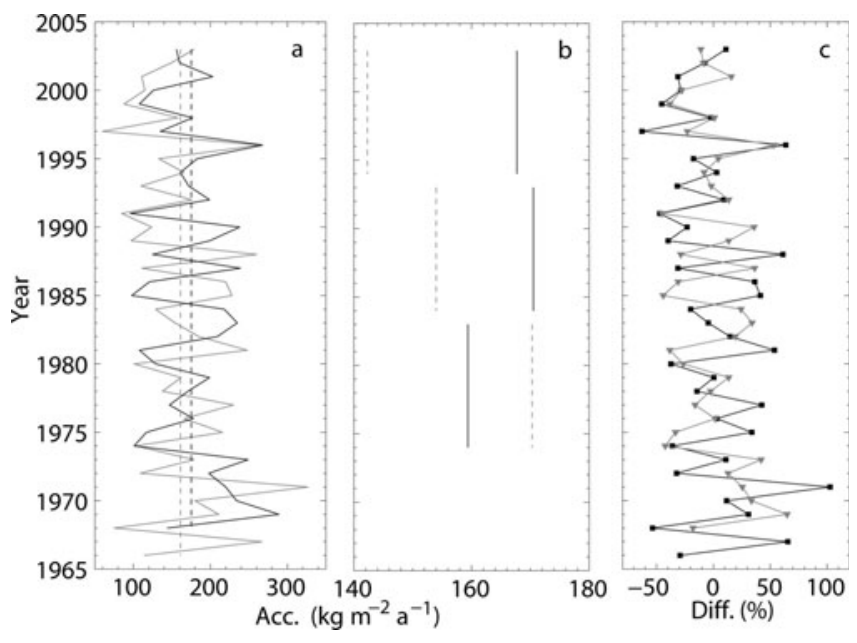

Fig. 5. (a) Year-to-year accumulation values obtained from firn cores F39 (black solid line) and F332 (grey solid line); the respective core means are depicted by the black dashed line (F39) and the grey dashed line (F332). (b) Accumulation rates for a 10 year mean for F332 (grey dashed line) and F39 (black solid line). (c) Variability expressed as per cent difference of the respective core mean. Grey line/grey triangles: F332; black line/black squares: F39.

been reported before in Antarctica (e.g. Black and Budd, 1964; Pettré and others, 1986; Goodwin, 1990; Vaughan and others, 2004; Eisen and others, 2005) and is attributed to wind influence (King and others, 2004) where accumulation maxima are located within surface elevation troughs and on the windward slopes. Local deviations from this general pattern in our data are possibly due to different local-scale near-surface winds. Another reason probably arises from the correction for glacier flow where we used a measured mean flow speed of $45 \mathrm{~m} \mathrm{a}^{-1}$ to correct the GPR layer depths and thus the accumulation pattern. Flow speed is not constant along the main flowline but increases with decreasing elevation. Measurements of spatial variations of ice flow are too inaccurate to allow a more detailed correction of the isochronal layers. Thus, accumulation maxima can be slightly misplaced due to locally incorrect consideration of glacier flow speed. However, the spatial variability of the accumulation rate is not affected by these errors.

\subsection{Comparison with other studies}

Other ground-borne data in this region are sparse, but there are a few accumulation values available from pit studies and stake readings.

Bormann and Fritzsche (1995) report a mean accumulation value derived from pit studies in the vicinity of a drillhole at $70^{\circ} 58^{\prime} \mathrm{S}, 11^{\circ} 22^{\prime} \mathrm{E}$, about $15 \mathrm{~km}$ north of our radar profiles $041201 / 041202$, that is about $130 \mathrm{~kg} \mathrm{~m}^{-2} \mathrm{a}^{-1}$ (1950-84) which is in accordance with our mean values.

The mean annual accumulation from the stake readings presented by Korth and Dietrich (1996) on the Insel traverse route (going from Novolazarevskaya station to Humboldtfjella; see Fig. 1a) is $131 \mathrm{~kg} \mathrm{~m}^{-2} \mathrm{a}^{-1}$, with a standard deviation of $140 \%$ because some of the stakes are located in an ablation area. This comparison should be viewed with caution since the stake readings cover the period 1988-93, so the time interval of the different accumulation values is not the same. Furthermore, Korth and Dietrich (1996) do not state actual values for the densities used to calculate the accumulation. However, their mean value is in the range of our mean

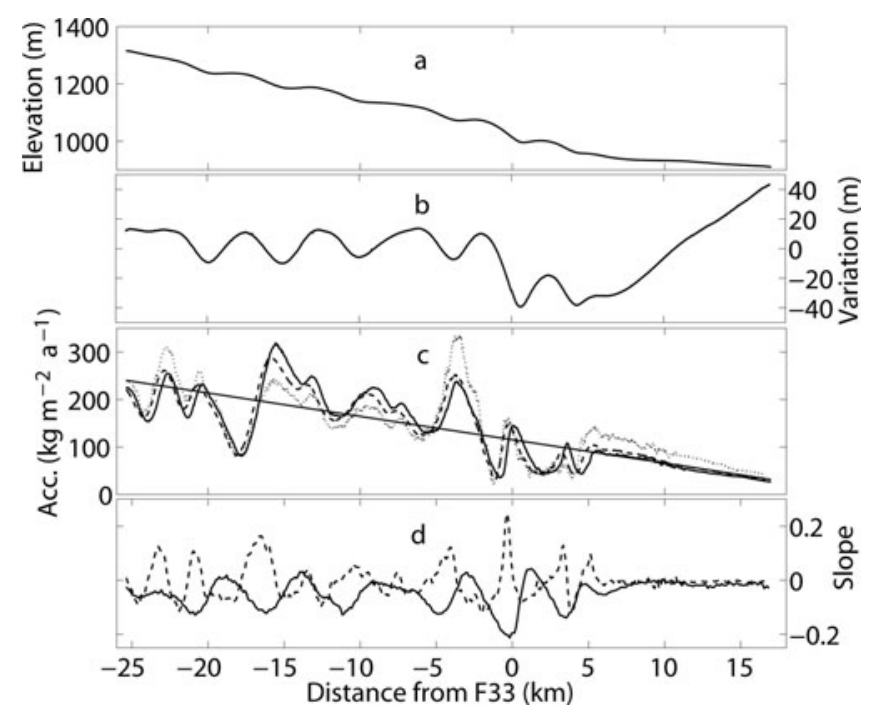

Fig. 6. (a) Surface elevation; (b) linearly detrended surface elevation; (c) accumulation pattern; and (d) gradient of accumulation and surface slope on the main flowline. The solid curve in (c) corresponds to the period 1980-2004, the dashed curve to 19702004 and the dotted curve to 1970-80. The solid line shows the linear trend fitted to the accumulation pattern. The solid line in (d) corresponds to the slope of surface elevation (vertically exaggerated by a factor of 5) in $\mathrm{m} \mathrm{m}^{-1}$, and the dashed line represents the slope of accumulation (1980-2004) in $\mathrm{kg} \mathrm{m}^{-2} \mathrm{a}^{-1} \mathrm{~m}^{-1}$.

values, indicating that the overall distribution of accumulation is quite stable for the different time periods, although there are obvious small-scale differences. Their values obtained at stakes in the vicinity of our profiles, about $1 \mathrm{~km}$ away from the main flowline, are $\sim 250 \mathrm{~kg} \mathrm{~m}^{-2} \mathrm{a}^{-1}$ which is much larger than our nearby values of $\sim 50 \mathrm{~kg} \mathrm{~m}^{-2} \mathrm{a}^{-1}$. Yet accumulation rates for the intervals 1980-89, 1980-92 and 1980-95 along profile 041201 (calculated from IRH Ia, Ib and Ic; see Fig. 2b) are 18-35\% higher than the other values in our study. Taking into account the report from Korth and Dietrich (1996), this might indicate a higher accumulation at this part of the glacier during the 1980s and early 1990s of about 25\% compared with the previous period (1970-80). Due to the dating uncertainty of F39, caution has to be used with these findings. However, dating uncertainty does not affect the accumulation pattern itself or the spatial variability which is clearly demonstrated by our study.

The accumulation values in the study area presented here are less than those reported by Giovinetto and Zwally (2000) who derive values of $\sim 200-250 \mathrm{~kg} \mathrm{~m}^{-2} \mathrm{a}^{-1}$ for this region of Antarctica. Vaughan and others (1999) report the same as Giovinetto and Zwally (2000). Both studies are concerned with larger areas and neglect small-scale features. Our mean value of $141 \mathrm{~kg} \mathrm{~m}^{-2} \mathrm{a}^{-1}(1970-2004)$ is less than these findings because there is an ablation area in the vicinity of our study area, which influences our results. Van de Berg and others (2006) derive specific surface mass balance (SSMB) from a regional atmospheric climate model, estimating precipitation, sublimation and melt. Snowdrift processes are not considered. The horizontal resolution is about $55 \mathrm{~km}$. They derive values of $\sim 200 \mathrm{~kg} \mathrm{~m}^{-2} \mathrm{a}^{-1}$ for the vicinity of our study area, which is likewise larger than our mean accumulation values. Our study reveals a significant influence of blowing snow on the accumulation values in the area of investigation, so neglecting this process likely 
results in an overestimated SSMB for this area as given by Van de Berg and others (2006). Large-scale compilations like those cited above are usually based on a limited number of scattered observations. They do not take into account the spatial representativity of the respective point measurements which may be obscured by local-scale variability. Our study demonstrates a very high spatial variability in this area of coastal DML and indicates a limited representativity of firncore derived accumulation data which are on average higher than the GPR-derived accumulation values. This might explain the higher accumulation rates in large-scale compilations of this area.

\subsection{Implications for satellite-data interpretation}

Satellite observations of surface elevation, for instance by European Remote-sensing Satellites- 1 and -2 (ERS-1/-2) and the Ice, Cloud and land Elevation Satellite (ICESat), and gravity from the GRACE mission (Tapley and others, 2004) can provide mass-distribution changes according to the mission-specific spatial and temporal resolutions. Combining GRACE data and altimetry data helps to discriminate ice-mass changes (Zwally and others, 2005) from height changes induced by glacial isostatic adjustment or by changes in snow and firn density (Wahr and others, 2000). However, the effective spatial resolution of GRACE monthly solutions is only several hundred kilometres. To account for the GRACE error behavior and to separate mass signals from different geographic origins, adapted filter techniques have to be utilized (Swenson and Wahr, 2002; Horwath and Dietrich, 2006b). Hence, GRACE provides only integrated mass-balance estimates over large areas.

Trends in ice-mass changes over a few years derived from satellite observations may be either due to interannual fluctuations in net ice surface mass balance or due to longterm ice dynamics. To distinguish between the two effects, information on the temporal and spatial covariance of the interannual surface mass-balance fluctuation is needed.

With regard to spatial covariance, Anschütz and others (2006) report spatial autocorrelation lengths of only about $1 \mathrm{~km}$ for surface mass-balance fluctuations. For values averaged over $\sim 100 \mathrm{~km}$ the small-scale variations (deposition noise) are averaged out, so the standard deviation of temporal fluctuations will be smaller than the values of 30$39 \%$ obtained from the firn-core time series (Table 2). Therefore, such small-scale fluctuations will not be resolved by GRACE. Concerning temporal covariance, there is, again, a large portion of small-scale deposition noise in the firncore data: the autocorrelation length of the firn-core time series is only 0.6 years (Fig. 5a). However, the accumulation pattern seems fairly stable on decadal scales (Fig. 5b).

The GRACE mission, launched in 2002, is planned to cover 8 years in total. Considering the discussion above, long-term surface mass-balance changes showing a considerably large spatial pattern would be sensed by GRACE. Hence, regional studies of mass fluctuations are very important to qualify the spatio-temporal behaviour of the ice surface mass balance in larger areas and to discriminate surface mass-balance fluctuations from long-term ice dynamics. In this context, the results presented by this study, combined with further estimates yielded by other authors for adjacent regions (e.g. Richardson-Näslund, 2001; Rotschky and others, 2004; Frezzotti and others, 2005), provide valuable ground-based information to validate and interpret GRACE observations.

\section{CONCLUSIONS}

We have combined GPR data and firn-core data to investigate the accumulation pattern on Potsdam Glacier. Accumulation rates show a very high spatial variability in the study area, with a standard deviation of almost $50 \%$. The generally decreasing trend of accumulation in the direction of glacier flow is overlain by local features. In accordance with other authors (Richardson-Näslund, 2001; Rotschky and others, 2004; Spikes and others, 2004; Arcone and others, 2005; Frezzotti and others, 2005), we conclude that it is important to take into account the spatial representativity of point measurements such as firn cores, snow pits or stake readings when examining accumulation rates.

Comparing the results from our study with previous work based on stake readings nearby, we found locally lower accumulation values; however, the previous study comprises a shorter time period. We found indications that accumulation during the late 1980s and early 1990s was slightly higher (about 25\% higher than in the period 1970-80). Large-scale studies of Antarctic accumulation show values of $200-250 \mathrm{~kg} \mathrm{~m}^{-2} \mathrm{a}^{-1}$ for our investigation area. The lower values found in our study are presumably owed to an ablation area that influences our results and has not been accounted for in the large-scale compilations, as well as significant influence of blowing snow on the local accumulation rates.

Our results provide useful insight into small-scale features affecting the accumulation in this area and can be helpful in further studies, especially for validating satellite-based massbalance estimates. Monitoring of local-scale accumulation changes in coastal areas provides valuable information to increase our knowledge of ice-mass fluxes from ice streams and outlet glaciers like Potsdam Glacier (Hamilton and others, 2005).

This study also complements published datasets and enhances the evaluation and interpretation of ice-mass changes in this area of East Antarctica.

\section{ACKNOWLEDGEMENTS}

This work was supported by the Deutsche Forschungsgemeinschaft (DFG) through the VISA project, funded under grants Di 473/17 and Jo 191/8. O.E. was supported by the DFG 'Emmy Noether' scholarship El 672/1. Comments from G. Hamilton, R. Pettersson and an anonymous reviewer greatly improved the manuscript. The contribution of the field team and help in the laboratory is gratefully acknowledged.

\section{REFERENCES}

Anschütz, H., O. Eisen, W. Rack and M. Scheinert. 2006. Periodic surface features in coastal East Antarctica. Geophys. Res. Lett., 33(22), L22501. (10.1029/2006GL027871.)

Arcone, S.A., V.B. Spikes and G.S. Hamilton. 2005. Stratigraphic variation in polar firn caused by differential accumulation and ice flow: interpretation of a $400 \mathrm{MHz}$ short-pulse radar profile from West Antarctica. J. Glaciol., 51(174), 407-422.

Bäßler, M., R. Dietrich and C.K. Shum. 2003. Investigations of ice dynamics at the grounding zone of an Antarctic ice shelf utilizing SAR-interferometry. In Jekeli, C., ed. Proceedings of the Weikko A. Heiskanen Symposium in Geodesy, 1-4 October 2002, Columbus, Ohio, USA. Columbus, OH, Ohio State University. Laboratory for Space Geodesy and Remote Sensing.

Black, H.P. and W. Budd. 1964. Accumulation in the region of Wilkes, Wilkes Land, Antarctica. J. Glaciol., 5(37), 3-15. 
Bormann, P. and D. Fritzsche, eds. 1995. The Schirmacher Oasis, Queen Maud Land, East Antarctica, and its surroundings. Gotha, Justus Perthes Verlag.

Damm, V. and D. Eisenburger. 2005. Ice thickness and sub-ice morphology in central Dronning Maud Land deduced by radio echo sounding. Geol. Jahrb., B97, 109-127.

Dietrich, R., R. Metzig, W. Korth and J. Perlt. 1999. Combined use of field observations and SAR interferometry to study ice dynamics and mass balance in Dronning Maud Land, Antarctica. Polar Res., 18(2), 291-298.

Eisen, O., U. Nixdorf, F. Wilhelms and H. Miller. 2002. Electromagnetic wave speed in polar ice: validation of the common-midpoint technique with high-resolution dielectricprofiling and $\gamma$-density measurements. Ann. Glaciol., 34, 150-156.

Eisen, O., U. Nixdorf, F. Wilhelms and H. Miller. 2004. Age estimates of isochronous reflection horizons by combining ice core, survey, and synthetic radar data. J. Geophys. Res., 109(B1), B01406. (10.1029/2003JB002858.)

Eisen, O., W. Rack, U. Nixdorf and F. Wilhelms. 2005. Characteristics of accumulation around the EPICA deep-drilling site in Dronning Maud Land, Antarctica. Ann. Glaciol., 41, $41-56$.

Frezzotti, M., S. Gandolfi and S. Urbini. 2002. Snow megadunes in Antarctica: sedimentary structure and genesis. J. Geophys. Res., 107(D18), 4344. (10.1029/2001JD000673.)

Frezzotti, M. and 13 others. 2005. Spatial and temporal variability of snow accumulation in East Antarctica from traverse data. J. Glaciol., 51(172), 113-124.

Fujita, S. and 6 others. 1999. Nature of radio-echo layering in the Antarctic ice sheet detected by a two-frequency experiment. J. Geophys. Res., 104(B6), 13,013-13,024.

Giovinetto, M.B. and H.J. Zwally. 2000. Spatial distribution of net surface accumulation on the Antarctic ice sheet. Ann. Glaciol., 31, 171-178

Goodwin, I.D. 1990. Snow accumulation and surface topography in the katabatic zone of eastern Wilkes Land, Antarctica. Antarct. Sci., 2(3), 235-242.

Hamilton, G.S., V.B. Spikes and L.A. Stearns. 2005. Spatial patterns in mass balance of the Siple Coast and Amundsen Sea sectors, West Antarctica. Ann. Glaciol., 41, 105-110.

Horwath, M. and R. Dietrich. 2006. Errors of regional mass variations inferred from GRACE monthly solutions. Geophys. Res. Lett., 33(7), L07502. (10.1029/2005GL025550.)

Horwath, M. and 7 others. 2006. Nivlisen, an Antarctic ice shelf in Dronning Maud Land: geodetic-glaciological results from a combined analysis of ice thickness, ice surface height and iceflow observations. J. Glaciol., 52(176), 17-30.

Isaksson, E. and W. Karlén. 1994. Spatial and temporal patterns in snow accumulation, western Dronning Maud Land, Antarctica. J. Glaciol., 40(135), 399-409.

King, J.C., P.S. Anderson, D.G. Vaughan, G.W. Mann, S.D. Mobbs and S.B. Vosper. 2004. Wind-borne redistribution of snow across an Antarctic ice rise. J. Geophys. Res., 109(D11), D11104. (10.1029/2003JD004361.)

Korth, W. and R. Dietrich. 1996. Ergebnisse geodätischer Arbeiten im Gebiet der Schirmacheroase/Antarktika 1988-1993. Bayer Akad. Wiss., Deut. Geod. Komm. B301.

Kreutz, K.J., P.A. Mayewski, L.D. Meeker, M.S. Twickler and S.I. Whitlow. 2000. The effect of spatial and temporal accumulation rate variability in West Antarctica on soluble ion deposition. Geophys. Res. Lett., 27(16), 2517-2520.

McMorrow, A.J., T.D. van Ommen, V. Morgan and M.A.J. Curran. 2004. Ultra-high-resolution seasonality of trace-ion species and oxygen isotope ratios in Antarctic firn over four annual cycles. Ann. Glaciol., 39, 34-40.

Melvold, K., J.O. Hagen, J.F. Pinglot and N. Gundestrup. 1998. Large spatial variation in accumulation rate in Jutulstraumen ice stream, Dronning Maud Land, Antarctica. Ann. Glaciol., 27, 231-238.
Meyer, U., D. Steinhage, U. Nixdorf and H. Miller. 2005. Airborne radio echo sounding survey in Central Dronning Maud Land, East Antarctica. Geol. Jahrb., B97, 129-140.

Oerter, H. and 6 others. 2000. Accumulation rates in Dronning Maud Land, Antarctica, as revealed by dielectric-profiling measurements of shallow firn cores. Ann. Glaciol., 30, 27-34.

Pettré, P., J.F. Pinglot, M. Pourchet and L. Reynaud. 1986. Accumulation distribution in Terre Adélie, Antarctica: effect of meteorological parameters. J. Glaciol., 32(112), 486-500.

Pinglot, J.F., J.O. Hagen, K. Melvold, T. Eiken and C. Vincent. 2001. A mean net accumulation pattern derived from radioactive layers and radar soundings on Austfonna, Nordaustlandet, Svalbard. J. Glaciol., 47(159), 555-566.

Richardson, C., E. Aarholt, S.E. Hamran, P. Holmlund and E. Isaksson. 1997. Spatial distribution of snow in western Dronning Maud Land, East Antarctica, mapped by a ground-based snow radar. J. Geophys. Res., 102(B9), 20,343-20,353.

Richardson-Näslund, C. 2001. Spatial distribution of snow in Antarctica and other glacier studies using ground-penetrating radar. (PhD thesis, Stockholm University.)

Rignot, E. and R.H. Thomas. 2002. Mass balance of polar ice sheets. Science, 297(5586), 1502-1506.

Rotschky, G., O. Eisen, F. Wilhelms, U. Nixdorf and H. Oerter. 2004. Spatial distribution of surface mass balance on Amundsenisen plateau, Antarctica, derived from ice-penetrating radar studies. Ann. Glaciol., 39, 265-270.

Sinisalo, A., A. Grinsted, J.C. Moore, E. Kärkäs and R. Pettersson. 2003. Snow-accumulation studies in Antarctica with groundpenetrating radar using 50, 100 and $800 \mathrm{MHz}$ antenna frequencies. Ann. Glaciol., 37, 194-198.

Spikes, V.B., G.S. Hamilton, S.A. Arcone, S. Kaspari and P. Mayewski. 2004. Variability in accumulation rates from GPR profiling on the West Antarctic plateau. Ann. Glaciol., 39, 238-244.

Swenson, S. and J. Wahr. 2002. Methods for inferring regional surface-mass anomalies from Gravity Recovery and Climate Experiment (GRACE) measurements of time-variable gravity. J. Geophys. Res., 107(B9), 2193. (10.1029/2001JB000576.)

Tapley, B.D., S. Bettardpur, M. Watkins and C. Reigber. 2004. The gravity recovery and climate experiment: mission overview and early results. Geophys. Res. Lett., 31(9), L09607. (10.1029/ 2004GL019920.)

Van de Berg, W.J., M.R. van den Broeke, C.H. Reijmer and E. van Meijgaard. 2006. Reassessment of the Antarctic surface mass balance using calibrated output of a regional atmospheric climate model. J. Geophys. Res., 111(D11), D11104. (10.1029/ 2005JD006495.)

Van der Veen, C.J. 2002. Polar ice sheets and global sea level: how well can we predict the future? Global Planet. Change, 32(2-3), 165-194.

Vaughan, D.G., J.L. Bamber, M.B. Giovinetto, J. Russell and A.P.R. Cooper. 1999. Reassessment of net surface mass balance in Antarctica. J. Climate, 12(4), 933-946.

Vaughan, D.G., P.S. Anderson, J.C. King, G.W. Mann, S.D. Mobbs and R.S. Ladkin. 2004. Imaging of firn isochrones across an Antarctic ice rise and implications for patterns of snow accumulation rate. J. Glaciol., 50(170), 413-418.

Wahr, J., D. Wingham and C. Bentley. 2000. A method of combining ICESat and GRACE satellite data to constrain Antarctic mass balance. J. Geophys. Res., 105(B7), 16,279-16,294.

Wilhelms, F. 1996. Leitfähigkeits- und Dichtemessung an Eisbohrkernen. Ber. Polarforsch. 191.

Wilhelms, F. 2005. Explaining the dielectric properties of firn as a density-and-conductivity mixed permittivity (DECOMP). Geophys. Res. Lett., 32(16), L16501. (10.1029/2005GL022808.)

Wingham, D.J., A.J. Ridout, R. Scharroo, R.J. Arthern and C.K. Shum. 1998. Antarctic elevation change from 1992 to 1996. Science, 282(5388), 456-458.

Zwally, H.J. and 7 others. 2005. Mass changes of the Greenland and Antarctic ice sheets and shelves and contributions to sealevel rise: 1992-2002. J. Glaciol., 51(175), 509-527. 